\title{
IT BALANCED SCORECARD IMPLEMENTATION TO MEASURE INFORMATION TECHNOLOGY PERFORMANCE ON INFORMATION TECHNOLOGY DIVISION OF PT. SAMUDERA INDONESIA TBK.
}

\author{
Mastuki \\ Information Systems Department, School of Information Systems, BINUS University \\ Jl. KH.Syahdan no.9 Kemanggisan Palmerah Jakarta Indonesia \\ mastuki07@gmail.com
}

\begin{abstract}
The goals of this thesis were to measure the performance of information technology in the IT Division of PT. Samudera Indonesia Tbk. using IT Balanced Scorecard (IT BSC), in which from each of its perspective was breakdown into related variables used as a model of optimal measurement. The problems that will be discussed in this research consisted of finding the factors required to measure the performance of information technology in the company; determining the indicators in measuring the IT performance; understanding in how to create the optimal measurement model of IT performance and evaluating how the measurement model affected the IT performance. The compiled data through questionnaires will be analyzed using factor analysis method through five steps: problem formulation, correlation matrix, determining the number of factors, factor rotation, and factor interpretation. The result of the research showed that there were four factors affected the IT performance in PT. Samudera Indonesia Tbk. which consist of IT Competency, IT Services Ability, Business Continuity and IT Improvement. Thus, it can be concluded that those factors affected the IT performance and to obtain a good quality of IT performance, each indicator of the factors should be done to the fullest.
\end{abstract}

Keywords: IT performance, IT balanced scorecard, confirmatory analysis factor

\begin{abstract}
ABSTRAK
Tujuan penulisan adalah untuk melakukan pengukuran kinerja teknologi informasi pada Divisi TI PT. Samudera Indonesia Tbk. dengan menggunakan IT Balanced Scorecard (IT BSC) yang kemudian dari setiap perspektifnya di turunkan ke dalam variabel-variabel terkait untuk dijadikan sebuah model pengukuran yang optimal. Masalah yang akan dibahas dalam penelitian ini adalah mencari faktor-faktor apa saja yang diperlukan untuk mengukur kinerja TI di perusahaan; menentukan apa saja yang menjadi indikator dalam melakukan pengukuran kinerja TI; mengetahui bagaimana membuat model pengukuran kinerja TI yang optimal di perusahaan; dan melihat bagaimana pengaruh model pengukuran terhadap kinerja TI. Data yang sudah terkumpul melalui kuesioner akan dianalisis dengan menggunakan metode analisis faktor melalui lima tahapan yaitu rumusan masalah, matriks korelasi, menentukan jumlah faktor, rotasi faktor dan interpretasi faktor. Hasil penelitian yang telah dilakukan didapatkan ada empat faktor yang mempengaruhi kinerja IT di PT. Samudera Indonesia Tbk. yaitu IT Competency, IT Services Ability, Business Continuity dan IT Improvement. Sehingga dapat disimpulkan bahwa faktor tersebut dapat mempengaruhi kinerja TI dan untuk mendapatkan kualitas kinerja TI yang baik setiap indikator pada faktor tersebut harus dilakukan secara maksimal.
\end{abstract}

Kata kunci: kinerja TI, IT balanced scorecard, analisis faktor 


\section{PENDAHULUAN}

PT. Samudera Indonesia Tbk. merupakan perusahaan publik yang bergerak dalam bidang pelayaran, transportasi dan logistik. Saat ini Samudera Indonesia Group merupakan perusahaan transportasi terpadu, yang memiliki beberapa anak perusahaan. Untuk dapat menyelaraskan dan mengintegrasikan induk perusahaan dengan anak perusahaan atau anak perusahaan dengan anak perusahaan serta dengan perusahaan-perusahaan terkait lainnya, PT. Samudera Indonesia Tbk. menggunakan Sistem Informasi (SI) dan Teknologi Informasi (TI) sebagai pendukung proses bisnis perusahaan agar dapat menghasilkan competitive advantage bagi perusahaan secara keseluruhan sehingga dapat bersaing dengan kompetitior lainnya.

Dalam menjalankan kegiatan di unit bisnisnya, Divisi TI masih perlu melakukan perancanaan dan menetapkan indikator, inisiatif atau kegiatan yang dapat menyelaraskan dan mendukung strategistrategi perusahaan secara keseluruhan dan untuk mengetahui indikator-indikator tersebut serta seberapa besar peran SI dan TI dalam menunjang pencapaian visi, misi dan strategi perusahaan maka perlu dilakukan pengukuran terhadap kinerja teknologi informasi yang ada di Divisi TI pada PT. Samudera Indonesia Tbk.

Dalam melakukan pengukuran kinerja TI pada perusahaan maka masalah yang akan dibahas dalam penelitian ini adalah: (1) Faktor-faktor apa saja yang diperlukan untuk mengukur kinerja TI di perusahaan? (2) Apa saja yang menjadi indikator dalam melakukan pengukuran kinerja TI? (3) Bagaimana membuat model pengukuran kinerja TI yang optimal di perusahaan? (4) Bagaimana pengaruh model pengukuran terhadap kinerja TI?

Tujuan penelitian terhadap kinerja TI pada perusahaan adalah: (1) Mencari faktor-faktor apa saja yang diperlukan untuk mengukur kinerja TI di perusahaan. (2) Mengetahui apa saja yang dapat dijadikan indikator dalam pengukuran kinerja TI. (3) Menghasilkan model pengukuran kinerja TI yang dapat digunakan secara optimal bagi perusahaan. (4) Mengetahui pengaruh dan hasil pengukuran dari model yang sudah dibuat.

Manfaat yang akan dirasakan perusahaan dari hasil penelitian adalah: (1) Dengan mengetahui faktor-faktor pengukuran kinerja IT, perusahan dapat melakukan justifikasi terhadap apa yang perlu dilakukan dan tidak dilakukan. (2) Dengan mengacu pada indikator kinerja maka proses akan berjalan dengan terkendali dan fokus dalam mencapai target yang telah ditetapkan. (3) Perusahaan memiliki model pengukuran yang dapat digunakan untuk mengukur kinerja TI secara optimal. (4) Dari hasil penelitian dapat diperoleh informasi apa saja yang dapat dijadikan pertimbangan sebagai dasar perumusan strategi perusahaan dari sisi SI/TI.

Visi, menurut Wibisono (2006), merupakan rangkaian kalimat yang menyatakan cita-cita atau impian sebuah organisasi atau perusahaan yang ingin dicapai di masa depan. Atau dapat dikatakan bahwa visi merupakan pernyataan want to be dari organisasi atau perusahaan. Visi juga merupakan hal yang sangat krusial bagi perusahaan untuk menjamin kelestarian dan kesuksesan jangka panjang. Misi, Menurut Wheelen sebagaimana dikutip oleh Wibisono (2006), merupakan rangkaian kalimat yang menyatakan tujuan atau alasan eksistensi organisasi yang memuat apa yang disediakan oleh perusahaan kepada masyarakat, baik berupa produk ataupun jasa.

Strategi, menurut Widjaja (2009), pada dasarnya adalah suatu teori tentang bagaimana mencapai sasaran perusahaan. Strategi merupakan alat untuk mencapai tujuan. Dalam perkembangannya, konsep mengenai strategi terus berkembang. Pengertian pengukuran kinerja menurut Mulyadi (2007) adalah penilaian kinerja sebagai penentu secara periodik efektivitas operasional suatu organisasi, bagian organisasi, dan karyawan berdasarkan sasaran, standar dan 
kriteria yang telah ditetapkan sebelumnya. Secara umum pengukuran kinerja merupakan suatu cara untuk mengukur arah dan kecepatan perubahan. Pengukuran kinerja sangat berperan nantinya dalam proses evaluasi kinerja perusahaan.

Sistem pengukuran kinerja sangat bermanfaat untuk mengetahui sejauh mana perusahaan telah berhasil mencapai tujuannya melalui strategi yang telah ditetapkan. Kaplan dan Norton (1992) mengembangkan sebuah konsep untuk melakukan pengukuran komprehensif agar dapat mengetahui bagaimana organisasi mencapai kemajuan lewat sasaran-sasaran strategisnya dan konsep tersebut dinamakan Balanced Scorecard. Berdasarkan Mulyadi (2005), Balanced Scorecard terdiri dari dua kata: kartu skor (Scorecard) dan berimbang (Balanced). Kartu skor adalah kartu yang digunakan untuk mencatat skor hasil kinerja seseorang. Kartu skor juga dapat digunakan untuk merencanakan skor yang hendak diwujudkan oleh personil di masa depan. Kata berimbang dimaksudkan bahwa kinerja personil diukur secara berimbang dari dua aspek, yaitu: keuangan dan non keuangan, jangka pendek dan jangka panjang, intern dan ekstern.

Balanced Scorecard terdiri atas tolok ukur keuangan yang menunjukkan hasil dari tindakan yang diambil sebagaimana ditunjukkan pada tiga perspektif tolok ukur operasional lainnya yaitu: kepuasan pelanggan, proses internal, dan kemampuan berorganisasi untuk belajar dan melakukan perbaikan.

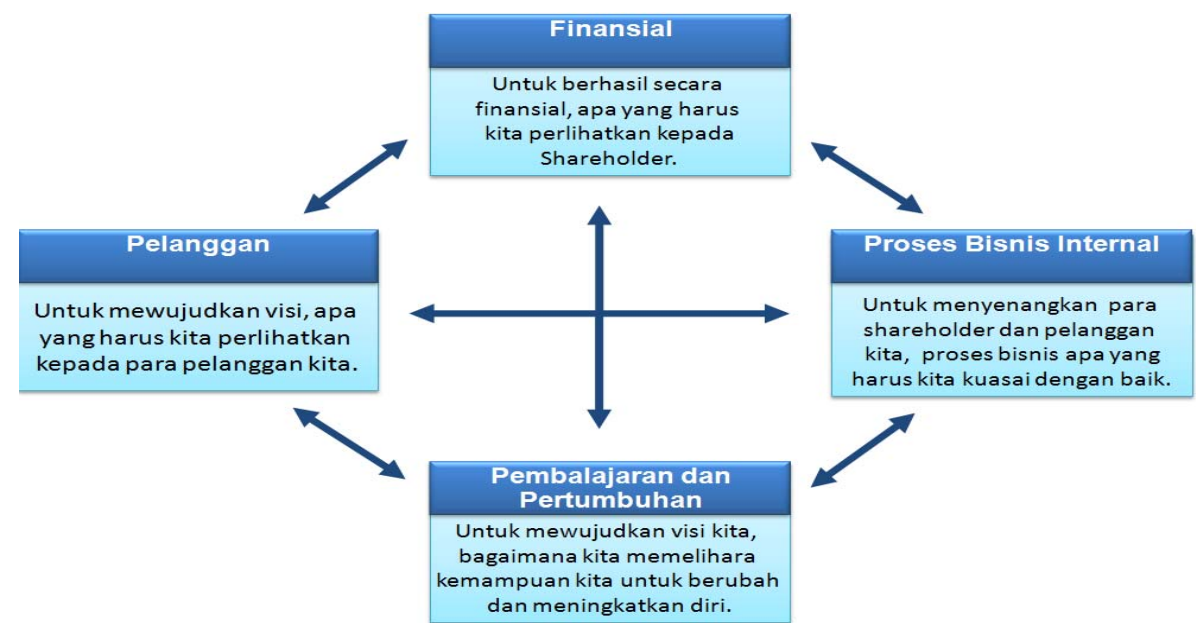

Gambar 1 Model Balanced Scorecard (Traditional BSC).

Grembergen dan Bruggen (1997) menyesuaikan Balanced Scorecard (model Kaplan \& Norton) untuk digunakan dalam teknologi informasi. Mereka mencatat bahwa departemen TI merupakan penyedia layanan internal, sehingga keempat perspektif tersebut disesuaikan dengan perubahan yang terjadi. Empat perspektif yang disesuaikan dalam IT BSC tersebut diantaranya adalah sebagai berikut: (1) Perspektif Kontribusi Perusahaan (Corporate Contribution), (2) Perspektif Orientasi Pengguna (User Orientation), (3) Perspektif Keunggulan Operasional (Operational Execllence), dan (4) Perspektif Orientasi Masa Depan (Future Orientation).

Tujuan dari Perspektif Kontribusi Perusahaan (Corporate Contribution) adalah untuk mencapai kontribusi bisnis terhadap investasi TI. Hal-hal yang dibahas dalam kontribusi perusahaan yaitu kontribusi strategis performance yang sinergis, nilai bisnis dari proyek TI dan manajemen dari investasi TI-nya. Tolok ukur yang digunakan berdasarkan standar obyektif yang tersedia atau yang dapat ditentukan dan kasus yang berasal dari sumber eksternal, (Saull, 2000). Sasaran pada perspektif kontribusi perusahaan yaitu mengendalikan biaya TI dari aplikasi TI yang baru dan nilai bisnis dari fungsi aplikasi TI yang sedang berjalan. 
Perspektif Orientasi Pengguna (User Orientation) difokuskan untuk mengevaluasi performance TI dari pandangan pelanggan dan pengguna internal (Karyawan Perusahaan) hal yang dibahas dalam orientasi pengguna yaitu kepuasan pelanggan, penggabungan TI, atau bisnis, keberhasilan pengembangan dan tingkat keberhasilan pelayanan. Ada tiga fokus yang perlu diperhatikan yaitu: menjadi penyedia aplikasi pilihan, bekerja sama dengan pengguna dan menjamin kepuasan pengguna. Hal ini bertujuan untuk memfokuskan pada pengembangan hubungan bisnis dan pengimplementasian organisasi TI yang baru beserta proses TI-nya.

Perspektif Keunggulan Operasional (Operational Execllence) menjelaskan tentang seberapa efektif dan efisien proses-proses TI dalam perusahaan. Fungsi TI harus memberikan pelayanan yang berkualitas tinggi kepada pengguna dengan biaya seminimal mungkin. Keunggulan Operasional memiliki kontribusi yang penting karena berakibat pada dua hal, yaitu: kualitas produk dan penekanan biaya TI. Apabila hal diatas kurang diperhatikan maka akibat yang akan ditimbulkan adalah beban kerja personil TI akan menjadi tinggi karena prosedur kerja kacau sehingga mengakibatkan banyak kesalah-pahaman dan pekerjaan ulang. Adapun faktor yang dibahas dalam Keunggulan Operasional yaitu proses yang cepat tanggap, pengelolaan jaminan dan perlindungan serta keamanan.

Perspektif Orientasi Masa Depan (Future Orientation) membahas tentang peningkatan kemampuaan perusahaan, keefektifan perusahaan manajemen karyawan, perkembangan arsitektur perusahaan dan penelitian terhadap teknologi-teknologi baru yang muncul. Rencana perusahaan dimasa yang akan datang harus dipersiapkan mulai dari sekarang. Perusahaan harus dapat membaca tren TI dimasa depan dan mengantisipasinya terlebih dahulu dengan penguasaan teknologi baru. Karena itu, penguasaan terhadap TI terbaru merupakan syarat mutlak untuk mendukung orientasi masa depan. Jadi solusi terbaik adalah dengan selalu mengadakan pelatihan personil TI secara tetap sehingga meningkatkan keahlian TI. Hal ini didukung dengan faktor teknologi juga, diantaranya melakukan penelitian teknologi informasi yang selalu up to date diharapkan dapat menjawab tantangan dimasa depan.

Menurut Grembergen dan Bruggen (1997) IT BSC merupakan metode pengukuran kinerja departemen TI dalam suatu perusahaan untuk melakukan evaluasi yang memberikan gambaran menyeluruh dan sesuai dengan bisnis inti masing-masing. IT BSC memberikan para eksekutif sebuah kerangka kerja secara keseluruhan, dimana visi dan strategi bisnis perusahaan disesuaikan dengan visi dan strategi TI di dalamnya.

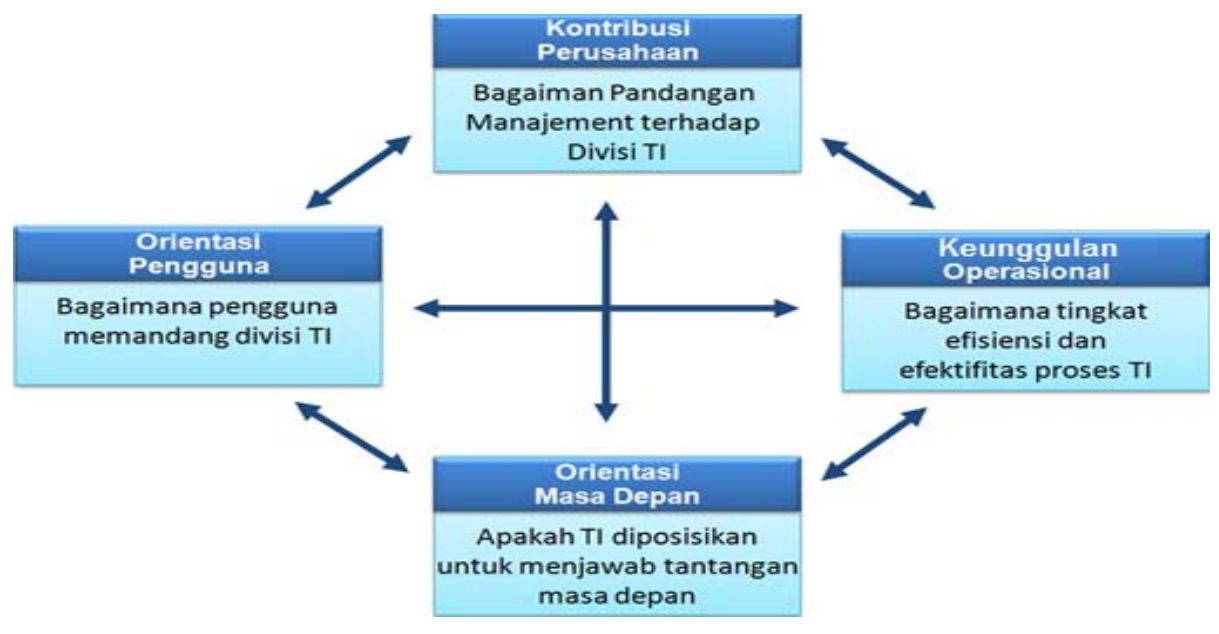

Gambar 2 Perspektif IT Balanced Scorecard 
Dari penjelasan tentang IT Balanced Scorecard (IT BSC) maka dapat dilihat bahwa perspektifperspektif yang ada merupakan hasil penyesuaian dari Traditional Balanced Scorecard (Traditional BSC), hal tersebut dapat dilihat pada gambar 3.

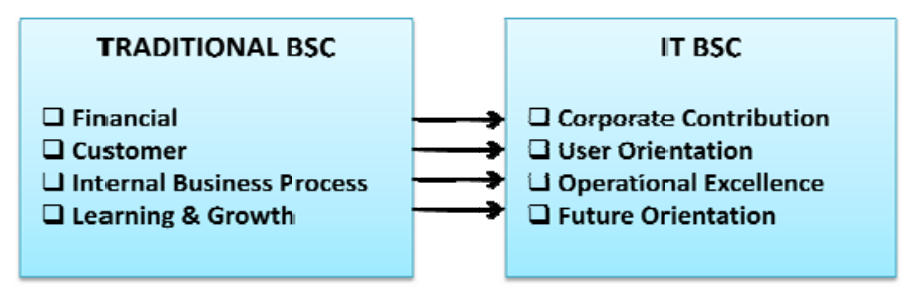

Gambar 3 Transformasi IT Balanced Scorecard

Uji Realibilitas digunakan untuk melihat kehandalan dari instrumen yang digunakan dalam penelitian, dengan cara menguji konsistensi pernyataan yang terdapat dalam variable bebas. Dengan mengamati nilai koefisien realibilitas (alpha) pada metode Cronbach's Alpha. Jika variabel mendekati nilai atau lebih besar sama dengan 0.7 maka data dapat dikatakan reliable (Sugiyono, 2007). Selain itu, nilai Measure of Sampling Adequacy (MSA) dan Kaiser-Meyer-Olkin (KMO) digunakan untuk mengetahui kecukupan data atau sample. Mengacu pada landasan teori bahwa sekelompok data dikatakan memenuhi asumsi kecukupan data adalah jika nilai MSA dan KMO lebih besar daripada 0.5 (Hair et al. 2006).

Hipotesis dari KMO adalah sebagai berikut :

Ho : Jumlah data cukup untuk difaktorkan

H1 : Jumlah data tidak cukup untuk difaktorkan

Statistik uji:

$$
\mathrm{KMO}=\frac{\sum_{i=1}^{p} \sum_{j=1}^{p} r_{i j}^{2}}{\sum_{i=1}^{p} \sum_{j=1}^{p} r_{i j}^{2}+\sum_{i=1}^{p} \sum_{j=1}^{p} a_{i j}^{2}}
$$

$i=1,2,3, \ldots, p$ dan $j=1,2, \ldots, p$

$\mathrm{r}_{\mathrm{ij}} \quad=$ Koefisien korelasi antara variabel $\mathrm{i}$ dan $\mathrm{j}$

$\mathrm{a}_{\mathrm{ij}} \quad=$ Koefisien korelasi parsial antara variabel $\mathrm{i}$ dan $\mathrm{j}$

Apabila nilai KMO lebih besar dari 0,5 maka terima Ho sehingga dapat disimpulkan jumlah data telah cukup difaktorkan.

Uji Bartlett bertujuan untuk mengetahui apakah terdapat hubungan antar variabel dalam kasus multivariat. Jika variabel $\mathrm{X}_{1}, \mathrm{X}_{2}, \ldots, \mathrm{X}_{\mathrm{p}}$ independen (bersifat saling bebas), maka matriks korelasi antar variabel sama dengan matriks identitas. Sehingga untuk menguji kebebasan antar variabel ini, uji Bartlett menyatakan hipotesis sebagai berikut :

$\mathrm{H}_{0} \quad: \rho=\mathrm{I}$

$\mathrm{H}_{1} \quad: \rho \neq \mathrm{I}$ 
Statistik Uji:

$$
\begin{aligned}
& \bar{r}_{k}=\frac{1}{p-1} \sum_{i=1}^{p} r_{i k}, k=1,2, \ldots, p \\
& \bar{r}=\frac{2}{p(p-1)} \sum \sum_{i<k} r_{i k} \\
& \hat{\gamma}=\frac{(p-1)^{2}\left[1-(1-\bar{r})^{2}\right]}{p-(p-2)(1-\bar{r})^{2}}
\end{aligned}
$$

Dengan:

$r_{\mathrm{k}} \quad=$ rata-rata elemen diagonal pada kolom atau baris ke $\mathrm{k}$ dari matrik $\mathrm{R}$ (matrik korelasi)

$r \quad=$ rata-rata keseluruhan dari elemen diagonal

Daerah penolakan :

tolak $\mathrm{H}_{0}$ jika

$$
\left.T=\frac{(n-1)}{(1-\bar{r})^{2}}\left[\sum \sum_{i<k}\left(r_{i k}-\bar{r}\right)^{2}-\hat{\gamma} \sum_{k=1}^{p} \bar{r}_{k}-\bar{r}\right)^{2}\right]>\chi^{2}(p+1)_{(p-2) / 2 ; \alpha}
$$

Maka variabel-variabel saling berkorelasi hal ini berarti terdapat hubungan antar variabel. Jika $\mathrm{H}_{0}$ ditolak maka analisis multivariat layak untuk digunakan terutama metode analisis komponen utama dan analisis faktor.

Analisis faktor adalah salah satu pendekatan multi-variabel analisis. Seperti disampaikan oleh Hair et al. (2006): Factor Analysis is a statistical approach that can be used to analyze interrelationship among a large number of variables and to explain these variables in term of their common underlying dimensions (factors).

Analisis faktor merupakan suatu cabang dari analisis variabel ganda yang memperhatikan hubungan internal dari sebuah himpunan variabel-variabel dimana hubungan tersebut dapat diartikan sebagai hubungan linier atau mendekati. Dalam analisis faktor ini seluruh variabel yang ada akan dilihat hubungan-nya (inter-dependent antar variabel), sehingga akan menghasilkan pengelompokan atau tepatnya abstraction dari banyak variabel menjadi hanya beberapa variabel baru atau faktor. Dengan sedikit faktor ini akan menjadi lebih mudah untuk dikelola dan diinterpretasikan. Tujuan utama dari analisis faktor adalah untuk menggambarkan keragaman diantara banyak variabel-variabel yang sebenarnya dapat dibedakan dalam beberapa sifat yang mendasar namun tidak dapat terobservasi kuantitasnya. Sifat yang mendasar namun tak dapat terobservasi kuantitasnya ini yang disebut faktor.

Skala terdiri dari pernyataan dan disertai jawaban setuju atau tidak setuju, sering atau tidak pernah, cepat atau lambat, baik atau buruk, dan sebagainya (tergantung dari tujuan pengukuran). Skala Likert menggambarkan secara kasar posisi individu dalam kelompoknya (posisi relatif), membandingkan skor subjek dengan kelompok normatifnya, menyusun skala pengukuran yang sederhana, dan mudah dibuat (Sugiyono, 2007). 


\section{METODE}

Dalam menyusun penelitian ini, kerangka berpikir yang akan digunakan adalah untuk menjawab pertanyaan bagaimana strategi perusahaan yaitu dari penerapan sistem informasi dan teknologi informasi, apakah efektif bagi perusahaan atau sejalan dengan tujuan perusahaan atau tidak. Untuk melakukan analisa efektifitas kinerja Teknologi Informasi pada Divisi TI secara keseluruhan, alat ukur yang akan digunakan adalah IT Balanced Scorecard. Dengan menggunakan framework IT Balanced Scorecard akan diperoleh tingkat kinerja dari sistem yang diterapkan secara berimbang dari empat persepektif sekaligus, yaitu dari perspektif kontribusi perusahaan, orientasi pelanggan atau pengguna, keunggulan operasional dan juga orientasi masa depan.

Berdasarkan penjelasan diatas maka penelitian pada studi kasus ini akan menggunakan faktorfaktor yang sudah ditentukan dan berasal dari studi pustaka sebagai cara untuk melakukan evaluasi kinerja TI dari sudut pandang pengguna internal. Lalu dengan melakukan analisa faktor pada faktorfaktor tersebut akan dicari tahu apa saja indikator yang terbentuk sehingga didapatkan faktor-faktor yang cocok dan model yang tepat untuk mengevaluasi kinerja TI di divisi TI pada PT Samudera Indonesia Tbk.

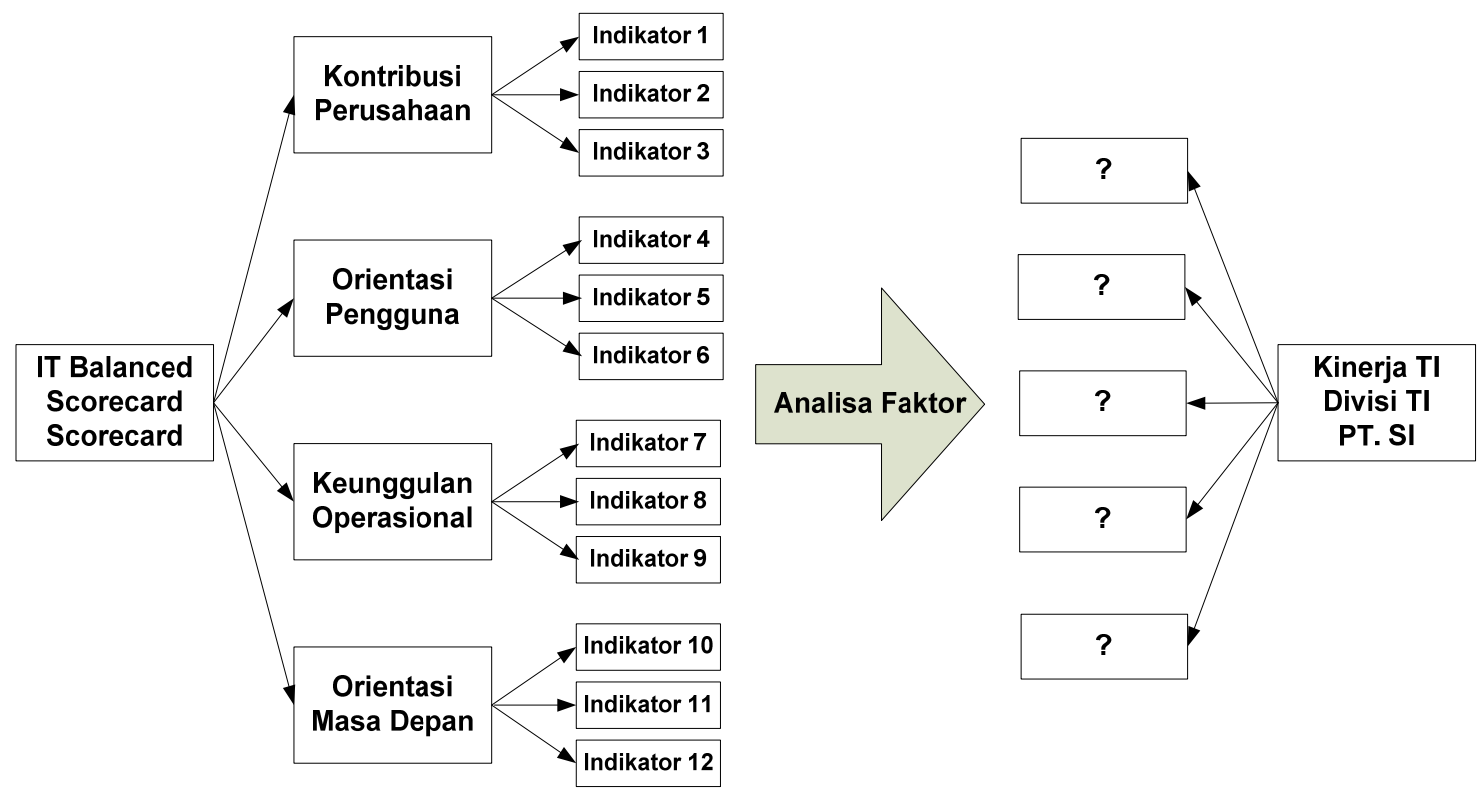

Gambar 4 Kerangka Pikir 


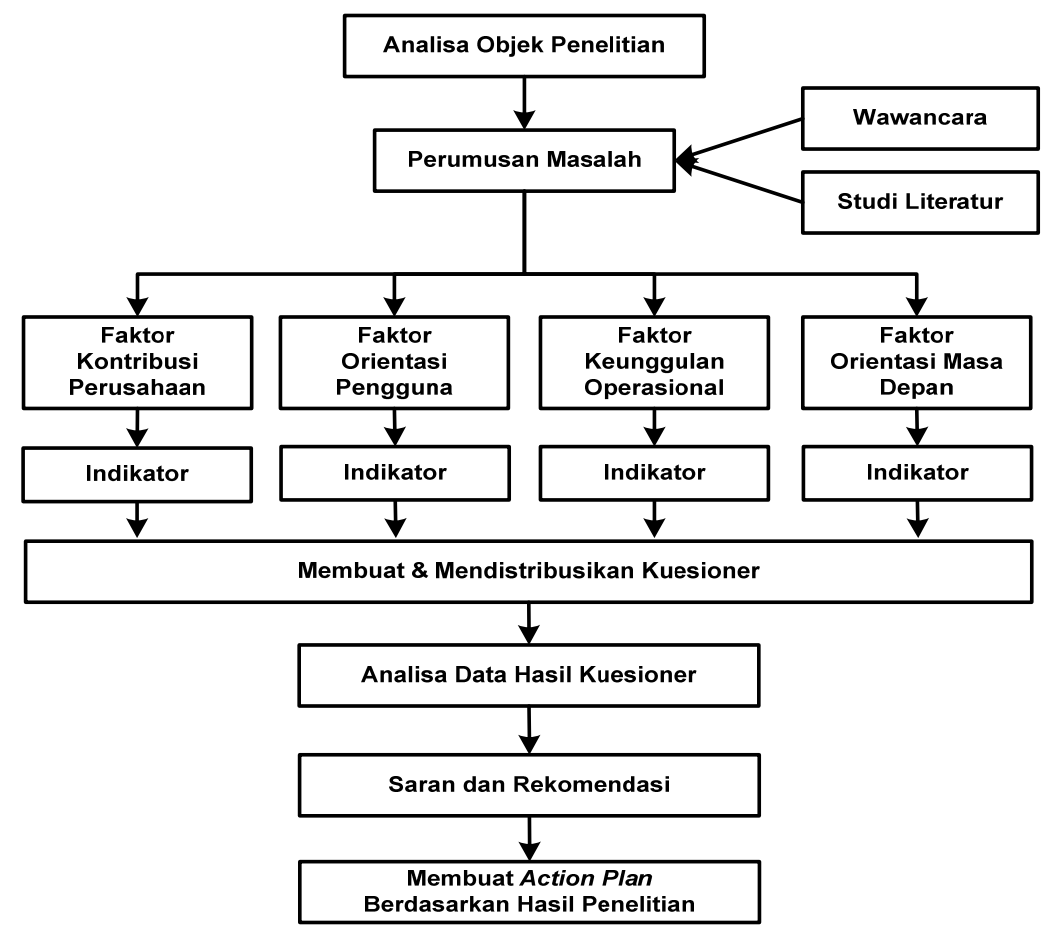

Gambar 5 Desain Penelitian

Dalam mengumpulkan data, dua macam metode pengumpulan data digunakan berdasarkan tempat penelitian, yaitu: (1) Studi Lapangan (Field Research) yaitu teknik pengumpulan data dengan cara melakukan penelitian ke lapangan atau ke perusahaan yang di jadikan objek penelitian secara lansung. Dalam teknik ini terdapat dua cara yang dilakukan yaitu Wawancara, Obeservasi dan Kuesioner. (2) Studi Kepustakaan (Library Research) adalah teknik pengumpulan data dengan cara membaca dan mempelajari sumber data yang digunakan berdasar data-data perpustakaan diantaranya artikel, buku, jurnal, literatur, internet dan laporan internal perusahaan.

Dalam mengolah data, penelitian ini menggunakan kuesioner sebagai instrumen pengumpulan data yang disebar kepada para responden. Pertanyaan-pertanyaan yang ada di dalam kuesioner tersebut dirancang sesuai dengan kebutuhan informasi yang diperlukan untuk keperluan pengujian analisa faktor dalam penelitian ini. Dalam pengukuran variabel, untuk mendapatkan informasi dari variabelvariabel digunakan nilai skala likert yang diberikan pada masing-masing jawaban untuk setiap pertanyaan pada kuesioner. Teknik skala yang digunakan dalam penelitian ini adalah intemized rating scales dengan menggunakan skala Likert (1-5). Untuk melakukan analisa data pada penelitian ini ada serangkaian tahap yang akan dilakukan yaitu uji Realibilitas dengan Cronbach Alpha, uji kecukupan data dengan KMO-MSA, uji korelasi variabel dengan Bartlett Test, analisis Faktor, dan regresi faktor dari Analisis Faktor dengan Factor Score.

Penelitian ini dilaksanakan di PT. Samudera Indonesia Tbk. Populasi dalam penelitian ini adalah para pegawai yang menggunakan atau berhubungan langsung dengan Divisi TI baik dari kantor cabang maupun kantor pusat. Dalam menguji realibilitas variabel yang ada atau uji coba kuisioner, dalam penelitian ini menggunakan SPSS untuk mendapatkan nilai Cronbach Alpha. Jika nilai Cronbach Alpha mendekati lebih besar dari 0,7 maka data dapat dikatakan reliable (Sugiyono, 2007). Uji KMO-MSA pada penelitian ini akan dilakukan dengan software applikasi SPSS. Apabila nilai KMO-MSA lebih besar dari 0,5 maka terima variabel H0 sehingga dapat disimpulkan data telah cukup untuk difaktorkan (Hair, 2006). Pada penelitian ini Uji Bartlett dilakukan dengan menggunakan applikasi SPSS. Jika nilai Sig kurang dari $\alpha=0.05$ yang berarti tolak H0. 


\section{HASIL DAN PEMBAHASAN}

Sejak tahun 1999 Samudera Indonesia terdaftar di Bursa Efek Indonesia sehingga pergerakan sahamnya dapat termonitor oleh masyarakat publik. Dan pada saat ini Samudera Indonesia memiliki empat lini bisnis utama yang menyediakan konektivitas global untuk pelanggan di Asia dan seluruh dunia, yaitu: pelayaran (Shipping), logistik (Logistics), terminal (Terminal) dan agensi (Agency). Armada kapal peti kemas beroperasi secara regional melalui hub Singapura dan secara domestik di Indonesia, dengan pelabuhan persinggahan termasuk di Timur Tengah (UEA, Iran \& Kuwait), the Indian Sub-Continent (India, Bangladesh, Pakistan \& Srilanka), Asia Tenggara (Singapura, Thailand, Malaysia, Vietnam, Myanmar \& Filipina) dan Timur Jauh (Cina, Korea, Hong Kong \& Taiwan). Untuk wilayah Indonesia, armada Samudera Indonesia beroperasi dari Jakarta ke Batam, Padang, Pontianak, Banjarmasin dan Balikpapan serta dari Surabaya ke Banjarmasin, Balikpapan, Samarinda dan Makassar.

PT. Samudera Indonesia Tbk. dalam bidang usahanya mempunyai visi, misi dan nilai-nilai yang diyakini oleh perseroan tersebut agar dalam menjalankan seluruh proses bisnisnya terarah dan sesuai dengan tujuan bisnis perusahaan. Visi PT. Samudera Indonesia Tbk.: Global connectivity to meet people needs. Maksud dari visi tersebut adalah Samudera Indonesia. ingin menjalin hubungan secara global baik lokal maupun internasional untuk memberikan atau mempertemukan kebutuhan setiap orang dengan lebih mudah dan lebih cepat. Misi PT. Samudera Indonesia Tbk.: Providing high quality services in goods transportation and logistics. Maksud dari misi tersebut adalah Samudera Indonesia harus dapat menyediakan layanan jasa transportasi dan logistik yang berkualitas tinggi bagi pelanggan, karena kepuasan pelanggan adalah prioritas utama yang menjadikan mereka merasa nyaman dan kemudian akan terus menggunakan jasa Samudera Indonesia.

Untuk mendapatakan hasil penelitian yang signifikan, maka kuesioner pada penelitian ini dibagikan kepada 75 orang responden, namun kuesioner yang kembali, datanya lengkap dan sesuai dengan kebutuhan penelitian adalah sebanyak 70 kuesioner. Setelah menganalisa dan mempelajari teori-teori yang ada dari buku maupun jurnal dan penelitian sebelumnya, maka di dapatkan beberapa faktor yang dapat digunakan dalam penelitian ini, faktor-faktro tersebut diantaranya adalah sebagai berikut : (1) faktor Kontribusi Perusahaan (Corporate Contribution), (2) faktor Orientasi Pengguna (User Orientation), (3) faktor Keunggulan Operasional (Operational Execllence), (4) faktor Orientasi Masa Depan (Future Orientation).

Dari keempat faktor di atas maka dilakukan analisa sehingga dihasilkan pernyataan dari indikator dan variabel-variabel yang akan dilanjutkan menjadi poin-poin dalam kuesioner yang kemudian dapat diolah lebih lanjut. Indikator dan variabel tersebut dapat dilihat pada tabel 1.

Tabel 1 Tabel Indikator

\begin{tabular}{|c|c|c|c|c|c|c|c|}
\hline $\mathrm{x}$ & & Perspective & & Objective & Indicator & Measures & Variabel \\
\hline \multirow{5}{*}{$\begin{array}{l}5 \\
0 \\
0 \\
0 \\
0 \\
0 \\
0\end{array}$} & \multirow{5}{*}{1} & \multirow{5}{*}{$\begin{array}{l}\text { CORPORATE } \\
\text { CONTRIBUTION }\end{array}$} & \multirow{4}{*}{1} & \multirow{4}{*}{ Strategic Alignment } & Leadership & Communication & $\mathrm{C} 1$ \\
\hline & & & & & Structure and process & $\begin{array}{l}\text { Understanding of Business Plan to } \\
\text { achieve organizational objective }\end{array}$ & $\mathrm{C} 2$ \\
\hline & & & & & Quality Standard & $\begin{array}{l}\text { Lack of knowledge about quality } \\
\text { standard }\end{array}$ & $\mathrm{C} 3$ \\
\hline & & & & & Value and belief & $\begin{array}{l}\text { Cultural and educational level and IT } \\
\text { utilization }\end{array}$ & $\mathrm{C} 4$ \\
\hline & & & 2 & Value Delivery & Operational Services & $\begin{array}{l}\text { Operation and maintenance of } \\
\text { Infrastructure }\end{array}$ & $\mathrm{C} 5$ \\
\hline
\end{tabular}


Tabel 1 Tabel Indikator (lanjutan)

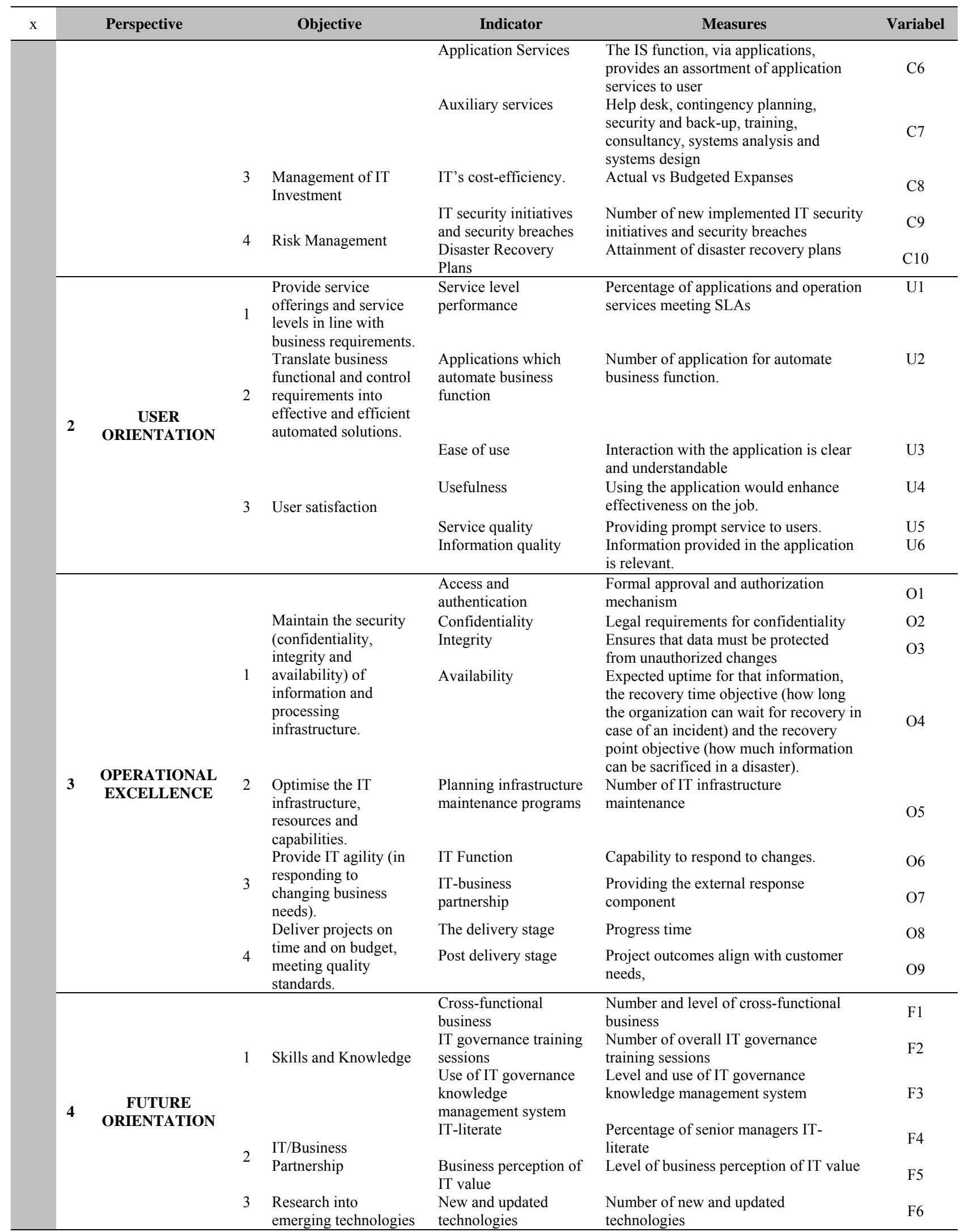


Batasan-batasan pada penelitian ini antara lain: (1) penelitian ini berfokus pada pengukuran kinerja IT pada Divisi TI dengan menggunakan faktor-faktor dari IT Balanced Scorecard, (2) metode pengumpulan data adalah kuesioner, yang berarti sangat tergantung dengan kualitas jawaban responden. (3) populasi penelitian ini hanya terbatas pada karyawan yang menjalankan fungsi bisnisnya berhubungan langsung dengan divisi TI atau difasilitasi oleh divisi TI.

Dari hasil uji reabilitas pada Tabel 2 menunjukan Alpha dari ke 31 variabel adalah sebesar 0,897 sehingga instrument yang digunakan dalam penelitian ini sudah dianggap reliable untuk pernyataan-pernyataan dalam masing-masing variabel yang digunakan dalam penelitian ini.

Tabel 2 Hasil Uji Reabilitas

\begin{tabular}{cc}
\hline Cronbanch's Alpha & N of Items \\
\hline 0.897 & 31 \\
\hline
\end{tabular}

Dari hasil pengolahan data yang dilakukan dengan menggunakan SPSS maka diperoleh KMO dari Barlett test sebagai kelayakan atau tidaknya faktor analisis dapat dilakukan. Diperoleh nilai KMO adalah 0.782 maka indeks dinyatakan tinggi dan faktor analisis layak dilakukan. Selanjutnya, nilai signifikasi adalah 0.000 yang menunjukan bahwa data yang dikumpulkan dapat diolah dengan menggunakan faktor analisis karena kurang dari $\alpha 0,05$.

Tabel 3 KMO and Bartlett's Test

\begin{tabular}{cc}
\hline KMO & $\mathbf{0 . 7 8 2}$ \\
\hline Sig. & 0.000 \\
\hline
\end{tabular}

Salah satu proses yang dilakukan pada analisa faktor adalah reduksi data, dari proses tersebutlah terjadi proses "penyaringan" komponen yang layak untuk dijadikan indikator, tentu dalam penelitian ini indikator yang dimaksud adalah indikator yang dapat dipakai untuk mengevaluasi kinerja TI. Pada penelitian ini faktor-faktor baru yang terbentuk dilakukan interpretasi terhadap faktorfaktor baru tersebut sesuai dengan pernyataan dari variabel yang mengelompok pada setiap faktor baru tersebut. Berikut adalah gambaran interpretasi dari faktor-faktor baru yang terbentuk: 

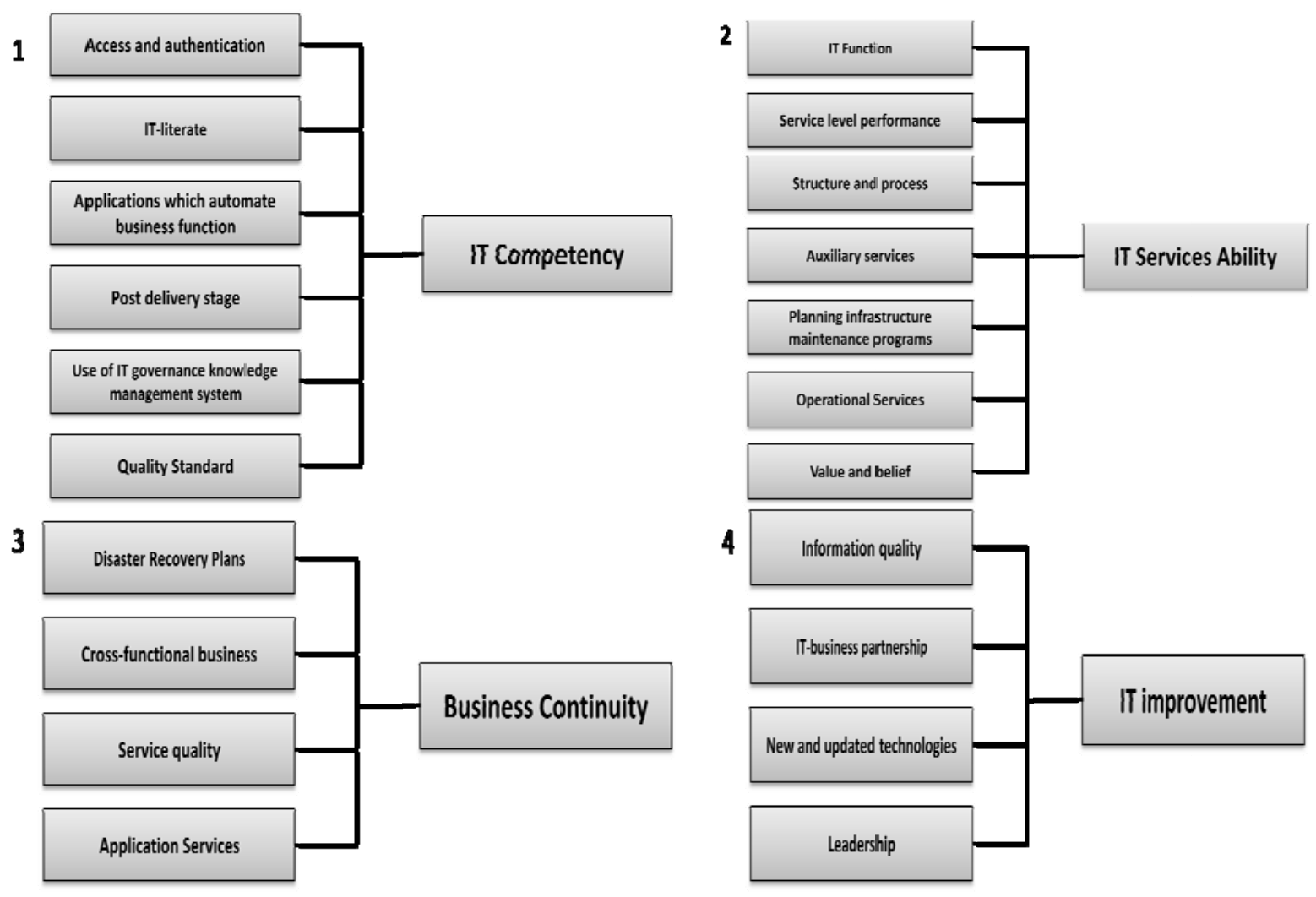

Gambar 6 Indikator \& Faktor Baru yang Dapat Berpengaruh Terhadap Kinerja TI

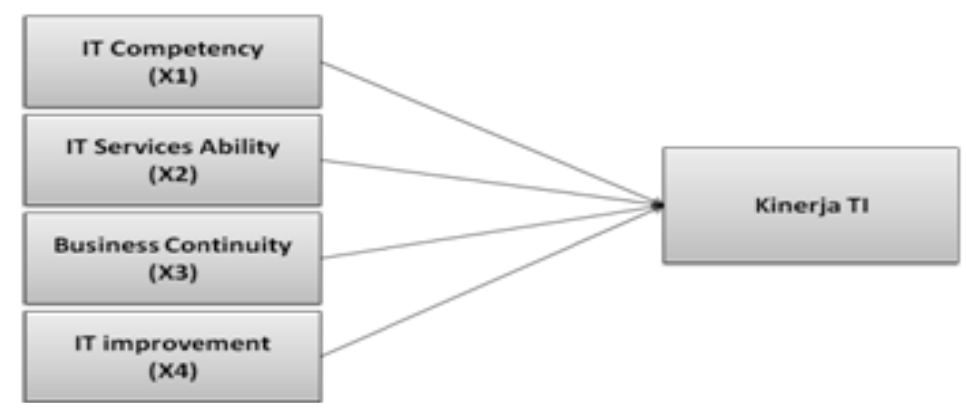

Gambar 7 Faktor yang Digunakan Dalam Model Pengukuran Kinerja TI

Gambar 7 menunjukkan faktor yang digunakan untuk melakukan pengukuran/evaluasi kinerja TI di perusahaan. Faktor-faktor terbentuk adalah IT Competency, IT Services Ability, Business Continuity dan IT improvement. Untuk mendapatkan faktor yang lebih dominan dan harus diperhatikan, dilakukan regresi antara faktor-faktor tersebut dengan dengan nilai kinerja IT menurut responden yang terdapat pada kuisioner.

Dalam kuisioner tersebut menggunakan 5 skala yaitu 0 - 19, $20-39,40-59,60-79,80-$ 100 agar dapat dilakukan analisa regresi, skala tersebut dikuantifikasi seperti terlihat pada tabel 4 . 
Tabel 4 Konversi Nilai Kinerja IT

\begin{tabular}{cc}
\hline Skala & Deskripsi \\
\hline $0-19$ & Buruk \\
$20-39$ & Kurang \\
$40-59$ & Cukup \\
$60-79$ & Baik \\
$80-100$ & Sangat Baik \\
\hline
\end{tabular}

Dari data penilaian kinerja yang diberikan respondens saat ini, kemudian dilakukan proses analisa lebih lanjut atas faktor IT Competency, IT Services Ability, Business Continuity dan IT Improvement yang terbentuk terhadap nilai kinerja TI. Kemudian setelah dilakukan proses perhitungan dan dari hasilnya dapat dilihat faktor pertama (X1) adalah 6.092; nilai faktor kedua (X2) adalah 3.747; nilai faktor ketiga (X3) adalah 3.696; nilai faktor keempat (X4) adalah 4.352; dan nilai constant (C) adalah 71.021.

\section{SIMPULAN}

Dari hasil penelitian dan pembahasan yang telah dilakukan maka dapat disimpulkan bahwa model yang terbentuk untuk melakukan pengukuran/evaluasi kinerja IT di divisi TI - PT. Samudera Indonesia Tbk. adalah diintepretasikan dengan formula sebagai berikut:

$$
\mathrm{F}(\mathrm{X})=71.021+6.092 \mathrm{X}_{1}+3.747 \mathrm{X}_{2}+3.696 \mathrm{X}_{3}+4.352 \mathrm{X}_{4}
$$

Dengan memasukkan nilai maksimum dan minimum ke dalam formula dan dilakukan perbandingan dengan tiga skenario, skenario pertama adalah tidak dilakukan penerapan dari faktor yang ada sama sekali, skenario kedua adalah menerapkan faktor $\mathrm{X}_{1}, \mathrm{X}_{2}, \mathrm{X}_{3}$ dan $\mathrm{X}_{4}$ dengan minimal nilai regresi faktor, dan skenario terakhir adalah melakukan menerapkan faktor $X_{1}, X_{2}, X_{3}$ dan $X_{4}$ dengan nilai regresi faktor maksimal. Dan hasil dari perhitungan tersebut didapatkan hasil $F(X)$ (Nilai Kinerja TI) yang gambarkan didalam tabel berikut:

Tabel 5 Nilai Evaluasi Kinerja IT

\begin{tabular}{cccccccc}
\hline No. & Kondisi & $\mathbf{F}(\mathbf{X})$ & $\mathbf{C}$ & $\mathbf{X}_{\mathbf{1}}$ & $\mathbf{X}_{\mathbf{2}}$ & $\mathbf{X}_{\mathbf{3}}$ & $\mathbf{X}_{\mathbf{4}}$ \\
\hline 1 & Saat ini & 71.021 & 71.021 & 0.000 & 0.000 & 0.000 & 0.000 \\
2 & Minimum & 23.448 & 71.021 & -2.099836 & -3.701484 & -2.608506 & -2.589660 \\
3 & Maximum & 111.143 & 71.021 & 2.507902 & 1.851823 & 1.989920 & 2.424292 \\
\hline
\end{tabular}

Dari data pada tabel 5 ada beberapa kondisi yang memungkinkan untuk terjadi, diantaranya adalah sebagai berikut: (1) Apabila tidak dilakukan penambahan atau pengurangan dari faktor-faktor yang didapatkan maka kinerja TI pada divisi TI akan mendapatkan nilai 71.021 yang berarti kinerja TI adalah baik, (2) Kondisi kedua adalah kondisi yang akan terjadi bila semua faktor berkurang dan mencapai titik terendah. Pada skenario di atas yaitu ketika divisi TI menerapkan faktor dengan nilai 
minimal maka kinerja TI akan mendapatkan nilai 23.448 yang berarti kinerja TI adalah kurang baik. (3) Kondisi ketiga adalah kondisi yang akan terjadi bila semua faktor ditingkatkan secara bersamaan dan mencapai titik tertinggi. Pada skenario diatas yaitu ketika divisi TI menerapkan faktor dengan nilai maksimal maka kinerja TI akan mendapatkan nilai 111.143 yang berarti kinerja TI adalah sangat baik.

Berdasarkan hasil analisa dari penelitian serta berbagai kekurangan maupun keterbatasan yang ada, maka saran yang dapat diberikan untuk perusahaan adalah sebagai berikut: (1) Dengan terbentuknya model yang ada, divisi TI kini diharapkan dapat melakukan perhitungan kinerja secara optimal. (2) Dalam melakukan tata kelola TI di divisi TI sebaiknya fokus terhadap permasalahan yang menjadi indikator-indikator pada IT Competency, IT Services Ability, Business Continuity dan IT improvement sehingga lebih terarah dalam melakukan aksi-aksi untuk meningkatkan kontribusi TI terhadap bisnis perusahaan. (3) Dari hasil analisa data, ada beberapa indikator yang tidak masuk pada proses analisa padahal berdasarkan studi literature, indikator tersebut perlu diterapkan. Indikator tersebut adalah IT's cost-efficiency, Confidentiality, Integrity, Availability, The delivery stage dan IT governance training sessions. Oleh karena itu, untuk kedepannya perusahaan sebaiknya memperhatikan hal-hal tersebut agar kinerja TI semakin meningkat.

Sedangkan untuk penelitian selanjutnya, disarankan untuk memperhatikan hal-hal sebagai berikut: (1) Keterbatasan waktu yang ada mempengaruhi jumlah sampel yang digunakan dalam penelitian ini, sehingga untuk penelitian selanjutnya disarankan untuk menggunakan sampel yang lebih banyak. (2) Jumlah total persentasi (\%) variance (kumulatif) yang terbentuk pada hasil penelitian masih kurang dari $100 \%$, menunjukkan masih terdapatnya faktor-faktor pengukuran kinerja IT lain yang belum terungkap, sehingga dapat dijadikan pertimbangan untuk penelitian selanjutnya. (3) Dapat menambahkan faktor-faktor lain sebagai faktor awal untuk melakukan pengambilan data kepada respondent survey.

\section{DAFTAR PUSTAKA}

Grembergen, W.V., Haes, S.D. (2005). Measuring and Improving IT Governance through the Balanced Scorecard. Information systems control Journal, 2.

Grembergen, W.V. (2002). The Balanced Scorecard and IT Governance. IT Governance Institute.

Grembergen, W. V., Saull, R. (2001). Aligning Business and Information Technology through the Balanced Scorecard at a Major Canadian Financial Group: its Status Measured with an IT BSC Maturity Model. Proceedings of the 34th Hawaii International Conference on System Sciences. University of Antwerp.

Grembergen, W.V., Saull, R. \& Haes, S.D. (2004). Linking the IT Balanced Scorecard to the Business Objectives at a Major Canadian Financial group. Journal of Information Technology Cases \& Applications, 5(1): 23.

Grembergen, W.V., Haes, S.D., \& Amelinckx, I. (2003). Using COBIT and the Balanced Scorecard as Instruments for Service Level Management. Journal of Information System Control, 4. Retrieved 11 May 2012 from http://www.isaca.org/Journal/Past-Issues/2003/Volume4/Documents/jpdf034-UsingCOBITandBSC.pdf 
Grembergen, W.V., Haes, S.D., \& Brempt, H.V. (2007). How Does the Business Drive IT? Identifying, Prioritising and Linking Business and IT Goals. Journal of Information System Control, 6. Retrieved 11 May 2012 from http://www.isaca.org/Journal/PastIssues/2007/Volume-6/Documents/jpdf0706-how-does-business.pdf

Grembergen, W. V., Bruggen, R. V. (1997). Measuring and improving corporate information technology through the balanced scorecard technique. Proceedings of the Fourth European Conference on the Evaluation of Information Technology, Delft, October 1997, pp. 163-171.

Hair, J. F., Anderson, R. E., Tatham, R. L. \& Black, W. C. (2006). Multivariate Data Analysis, Sixth Edition, London: Prentice Hall International.

Kaplan, R. S., Norton, D. P. (1992). The Balanced Scorecard - Measure that Drive Pervormance. Harvard Business Review.

Kaplan, R. S., Norton, D. P. (1992). Alignment Is Not Enough: Integrating Business and IT Management with the Balanced Scorecard. Proceedings of the 1st Conference on the IT Balanced Scorecard. Harvard Business Review.

Kaplan, R. S., Norton, D. P. (2008). Mastering the Management System. Harvard Business Review.

Mulyadi. (2005). Sistem Manajemen Strategik Berbasis Balanced Scorecard. Yogyakarta: Sekolah Tinggi Ilmu Manajemen YKPN.

Mulyadi, (2007). Sistem Perencanaan dan Pengendalian Manajemen. Jakarta: Salemba Empat.

Saull, R. (2000). The IT Balanced Scorecard, A Roadmap to Effective Governance of a Shared Services IT Organization. Journal of Information System Control, 2.

Sugiyono. (2007). Statistika Untuk Penelitian. Bandung: CV Alfabeta.

Wibisono, D. (2006). Manajemen Kinerja. Jakarta: Erlangga.

Widjaja, A. (2009). Performance Measurement and Balanced Scorecard. Jakarta: Harvarindo. 